\title{
Designing an online learning environment on Open Educational Resources for science education
}

\author{
Shironica Karunanayaka \\ The Open University of Sri Lanka, Sri Lanka \\ Chandana Fernando \\ The Open University of Sri Lanka, Sri Lanka \\ Vajira de Silva \\ The Open University of Sri Lanka, Sri Lanka
}

\begin{abstract}
The concept of Open Educational Resources (OER) is a major breakthrough in education, which promotes sharing, adaptation and contextualisation of course content. Promotion of using OER can be very cost effective, since development of new course content would be both expensive and time consuming. However, awareness raising and capacity building of teachers and learners is crucial, in order to exploit the full potential of OER.

The Faculty of Education at the Open University of Sri Lanka, initiated a research project to create an Online Learning Environment (OLE) on OER for science education, with a view to raise awareness, develop competencies and enhance adapting, adoption and creation of OER by teachers. This is developed in Moodle Learning Management System, as a supplementary material for science teachers enrolled in a distance mode professional development programme. The research team, together with a group of science teachers and teacher educators, who are their students, is engaged in this action research conducted in several stages: analysis, design, development, implementation and evaluation. This paper discusses the first three stages, concerning the following objectives: to identify sources of OER for science education, to make key design decisions of the OLE, and to design and develop the OLE on OER for science education.
\end{abstract}

The analysis of need, learner, task and context, resulted in making decisions on information, instruction, interaction and interface design. Some initial design decisions are: Structuring of information on finding, using and creating OER related to teaching science, while making it relevant and meaningful for teachers; Use of exploratory instructional strategies enabling teachers to select OER; Incorporate frequent interactions encouraging teachers to adopt, adapt, create and share OER; and Use of different media elements to make the visual layout motivating. A prototype will be pilot tested with science teachers with a view to revise and improve the OLE on OER. Allowing student teachers/teacher educators to work collaboratively with their instructors, as a team, enable both parties to face challenges together, in this novel experience of designing and developing an OLE on OER. 


\section{Introduction}

The concept of Open Educational Resources (OER) is a major breakthrough in education, which promotes sharing, adaptation and contextualisation of course content. OER are defined as teaching, learning and research materials in any medium that reside in the public domain, and have been released under an open license that permits access, use, repurposing, reuse and redistribution by others with no or limited restrictions (Atkins, Brown \& Hammond, 2007). These can include full courses/programmes, course materials, modules, student guides, teaching notes, text books, research articles, videos, assessment tools and instruments, interactive materials such as simulations, role plays, databases, software, applications (including mobile apps) and any other educationally useful materials (UNESCO, 2002). Thus, OER can make a significant contribution in teaching and learning, by making a variety of educational resources easily and freely available.

Promotion of use and adaptation of OER can be a very cost effective way for instructional material development. Since development of new course content would be both expensive and time consuming, it would be far more beneficial for educators to use OER, rather than duplication of already available materials. Recently, there has been a constantly growth in the supply of OER materials available on the Internet, both as formal course materials as well as informal, non-course materials (Hatakka, 2009). A vast majority of open content are produced, however, in developed countries, while there are limited open content initiatives reported from developing countries (Wiley, 2006). It has also been identified that the use of open and free content is very low by educational institutions in developing countries (Hatakka, 2009), due to various reasons. It has been suggested that to reach its full potential, a global balance is needed, where developing countries would not be confined to being only consumers of OER, but also producers (Albright, 2005). Awareness raising and capacity building of teachers and learners is crucial, in order to exploit the full potential of OER.

The Faculty of Education at the Open University of Sri Lanka, initiated a research project to create an Online Learning Environment (OLE) on OER for science education, with a view to raise awareness, develop competencies and enhance adapting, adoption and creation of OER by teachers. This is developed in Moodle Learning Management System (LMS) for science teachers enrolled in a distance mode professional development programme. The research team, together with a group of science teachers/teacher educators who are also their learners, is engaged in this research project conducted in several stages: analysis, design, development, implementation and evaluation. This paper discusses the first three stages of the on-going project. 


\section{Review of Literature}

The historical development of the free and open learning resources can be traced back to 1998, when the concept of 'open content' was introduced by David Wiley through development of learning objects to enable construction of educational materials easily, through a repository of such objects (Wiley, 2006). Later, in 2001, the Massachusetts Institute of Technology took measures to create 'Open CourseWare', making the content developed by their faculty freely available on the web under an open license (MIT-OCW, 2007). The term 'Open Educational Resources' (OER) was coined at a UNESCO Forum in 2002, and is now widely popular globally (UNESCO, 2002). The increasing pool of OER not only widens educators' choice of resources, but also creates opportunities for new resources to be adapted to fit the local context in terms of culture and learning needs- without necessitating lengthy copyright negotiations or duplicating content development (UNESCO, 2011).

The Open University of the United Kingdom (OUUK), through a large institutional action research project, has devised its 'OpenLearn' website (www.open.ac.uk/openlearn) producing an integrated set of learning resources in a variety of formats as OERs. They have identified three models for transformation of their materials as OER: The Integrity Model, The Essence Model and The Remix model (Lane et al, 2010). Addressing the needs of the members of their learning communities, The Open University of Japan has constructed a learning object repository to promote sharing, distribution and reuse of learning objects prepared by them. Furthermore, they have created a cross-institutional search system - 'JOCW search', to provide users of their courseware a gateway to the courseware of other universities (Morimoto \& Yamada, 2011).

Indira Gandhi National Open University (IGNOU) has created multimedia digital learning repositories, 'e-Gyankosh' being the key resource, with the purpose of encouraging use, sharing, re-use and editing of the resource by other institutions and learners (Kanjilal, 2007; Thomas $\&$ Kothari, 2011). An initiative made at IGNOU to develop a sustainable training system for continuous professional training of elementary school teachers on using 'wiki' to collaboratively develop materials which will be a national OER, has been claimed as successful in generating immense interest among teachers in this regard (Singh, 2011). Misra (2011) discusses possible ways of making teachers competent in using and producing OER, by making OER training an integral part of teacher training programmes.

Based on the services provided, Kanjilal (2007) had categorised digital learning repositories into three types: Online catalogue of web-based resources (e.g., MERLOT <http://www. merlot.org>; Online digital object repositories (e.g., MIT Open Courseware <http://ocw. mit.edu/index.html $>$ and Online learning repositories (e.g., Connexions <http://cnx.rice. edu >). Similarly, a very broad categorisation of OER providers has been presented by Joyce (2007) by organising them by provider and scale of operations. Accordingly, the provider can be either repositories where educational institutions make their open content available (e.g., MIT OCW) or community repositories that anyone can add content to (e.g., Wikipedia). Also according to the amount of content in repositories, the scale of operation may be either small (e.g., OpenCourse.org) or large (e.g., MERLOT) (Joyce, 2007). 
The Institute for the Study of Knowledge Management in Education (ISKME, 2008) reports six case study projects on creation, use and reuse of OER- namely, CurriculumNet in Uganda, Free High School Science Texts (FHSST) in South Africa, Training Commons in India, Curriki, Stanford Encyclopedia of Philosophy and Teacher's Domain in United States. These studies addressed a wide range of themes from content production and licensing to user engagement, to financial sustainability, ensuring resource adaptability, and conducted using a participatory methodology parallel to an empowerment model. Findings implied that an important aspect of project sustainability was implementation of shared, collaborative and peer-based practices (ISKME, 2008).

Teacher Education in Sub-Saharan Africa (TESSA) is a research and development network with the main purpose of improving the quality of, and extend access to, teacher education in Sub-Saharan Africa. Among several others, it included a secondary science teacher education project aimed at creating OER to support pre-service teachers in developing learner-centred pedagogical approaches to teaching science in secondary schools across Uganda, Kenya, Ghana, Zambia and Tanzania, while increasing their awareness of participatory pedagogies (Wolfenden, Buckler \& Keraro, 2010).

There is a dearth of research conducted on OER in Sri Lanka. Findings of a case study conducted by Hatakka (2009) in Sri Lanka and Bangladesh on the use of open content by content developers has revealed several inhibiting factors that prevent course designers from using OER. Educational rules and restrictions, English language problems, lack of relevance, difficulty in access, problems with technical resources, concerns about quality, concerns about copyright issues, lack of awareness, limitations in computer literacy, teaching capacity and teaching practices and traditions are the key inhibiting factors identified in this study. Based on the findings of the above case study, the author concludes that although development of more open content and content of high quality material is needed, but "building it" will only address a small portion of the inhibiting factors that content developers face in using OER (Hatakka, 2009). Thus it is evident that effective advantage of OER can be realised only through systematic design and creation of quality OER, that would cater for specific requirements. Furthermore, the need for raising awareness among educators in Sri Lanka about OER and encouraging use and creation of OER within the country is also implied.

Design and development of computer-based learning materials has been identified as a highly challenging and motivating task for educators, which results in building up their selfconfidence in integrating computer technology into teaching and learning. (Karunanayaka, 2005; Karunanayaka, 2006). Case studies on implementation of an online course for teacher educators have revealed that the interactive online learning environment has supported collaborative learning among educators and this developing their confidence in self-regulated and reflective learning (Karunanayaka, 2008a; Karunanayaka, 2008b). Moreover, an in-depth study on design features of online courses developed by educators revealed that designers faced several challenges in creating meaningful online learning environments, and emphasised the need to pay attention on using appropriate instructional design approaches (Karunanayaka \& Thanaraj, 2010). 


\section{Methodology}

The research project aims at designing, developing and evaluating an Online Learning Environment (OLE) on OER for science education, with a view to raise awareness, develop competencies and enhance use and creation of OER by teachers. The specific objectives of the study are to:

1. Identify sources of Open Educational Resources (OER) for science education.

2. Design an Online Learning Environment (OLE) on OER for science education.

3. Develop the OLE on OER with the participation of student teachers/teacher educators together with their instructors.

4. Evaluate the OLE on OER and make further improvements as required.

The study is conducted in several stages based on the instructional systems design (ISD) model, ADDIE model: Analysis, Design, Development, Implementation and Evaluation (NIIT, 2004). The three-member research team is involved in this process with the involvement of four science teachers/teacher educators, who are postgraduate level students at the Faculty of Education, OUSL. They were selected through the purposive sampling method, via a preliminary questionnaire survey and interviewing.

During the Analysis phase, the project team engaged in need analysis, learner analysis, task analysis and context analysis. A comprehensive review of literature and an extensive online search on available OER on science education was conducted and appropriate sources of OER for science education were identified, based on which preliminary design and development decisions were made. Through shared responsibilities, the team worked on fulfilling the targeted activities using a participatory approach.

Designing phase involved writing objectives, structuring the content, selecting an instructional approach and designing graphical user interface. Development included writing a storyboard, integrating course content in different media formats, designing navigation structure, incorporating strategies to enhance interactivity, and constructing the OLE, named "OER4ScEd", in Moodle LMS. Formative evaluation was done while OER4ScEd is being developed, through data collected by means of self-reflections of the project team, regular focus group discussions and obtaining peer reviews which provided useful feedback to revise, refine and improve it. A prototype will be pilot tested with a selected group of Science teachers before finalising. 
Since this is an ongoing project, this paper discusses the findings of first three stages, concerning identifying sources of OER for science education, making key design decisions of OER $4 S c E d$, and developing a prototype of $O E R 4 S c E d$ to be user-tested. The following research questions guided this process:

1. What processes and structures will best facilitate teachers to identify, adopt and adapt OER?

2. How to ensure that the content is relevant and adaptable to user needs?

3. How to facilitate user engagement and collaboration in content creation?

\section{Results and discussion}

The analysis of the need, learner, task and the context, resulted in making initial design and development decisions by the research team, as indicated in Table 1.

\begin{tabular}{|l|l|l|}
\hline Aspect of Analysis & \multicolumn{1}{|c|}{ Description } & Design/Development decisions \\
\hline Need & $\begin{array}{l}\text { A need for awareness raising } \\
\text { and facilitating teachers/teacher } \\
\text { educators to use and create OER }\end{array}$ & $\begin{array}{l}\text { - Design and develop an OLE on } \\
\text { OER for Science Education in } \\
\text { Moodle LMS - "OER4SCEd" }\end{array}$ \\
\hline Learner & $\begin{array}{l}\text { Adult learners of OUSL professional } \\
\text { development programmes, who } \\
\text { are educators engaged in teaching } \\
\text { or teacher education in Science }\end{array}$ & $\begin{array}{l}\text { - Use androgogy (adult learning) } \\
\text { assumptions }\end{array}$ \\
\hline - Align theory with practice \\
\hline Context & $\begin{array}{l}\text { Learners need to engage in search/ } \\
\text { adopt/adapt/create OER }\end{array}$ & $\begin{array}{l}\text { - Experiential learning strategies } \\
\text { - A participatory model } \\
\text { - An iterative and a collaborative } \\
\text { process }\end{array}$ \\
\hline
\end{tabular}

Table 1 Design/Development decisions made during the Analysis Phase

Based on the analysis, the project team decided to design and develop OER4ScEd, initially focusing on Grades 10-11 National Curriculum on Science, related to topics in three subject areas: biology, chemistry and physics. Some key considerations in resource selection were; relevance, simplicity in use, catering to different learning styles (visual/auditory/kinesthetic) through informative illustrations, animated content, audio content, interactive videos, knowledge construction through games, real world examples and assessment activities with answers and explanations. 
During the design and development phase, a prototype of OER4ScED was produced in Moodle. The main considerations were, how information is structured sequenced and organised, how instructions/guidance are provided, how teachers are encouraged to interact with the material, the visual appearance, how to motivate teachers and enhance their participation/interactions, and how to encourage them to create and share OER. The key considerations of design features are summarised in Table $\mathbf{2}$.

\begin{tabular}{|c|c|c|}
\hline Design Aspect & Description & Considerations \\
\hline Information Design & $\begin{array}{l}\text { Strategies to present } \\
\text { information }\end{array}$ & $\begin{array}{l}\text { - Content structured in } 06 \text { main sections: } \\
\text { - } 1 \text { - An introductory section on OER - } \\
\text { to raise awareness, develop skills and } \\
\text { facilitate search/use/creation of OER } \\
\text { - } 2-4-\text { Subject-wise sections with } \\
\text { selected OER - Biology/Chemistry/ } \\
\text { Physics } \\
\text { - } 5 \text { - General resources section to } \\
\text { search and find OER } \\
\text { - } 6 \text { - Section to Create/Add OER } \\
\text { - Chunking; labeling; sequencing; } \\
\text { layering of resources } \\
\text { - Chunking Subject-wise/Topic-wise } \\
\text { - Labeling meaningfully } \\
\text { - Sequencing according to stated } \\
\text { competencies/topics in curriculum } \\
\text { - Consistency in layering in the Subject- } \\
\text { wise sections: } \\
\text { - Lessons/Presentations } \\
\text { - Activities/Assessments } \\
\text { - Multimedia }\end{array}$ \\
\hline Instruction Design & Instructional strategies & $\begin{array}{l}\text { - Learner-centred; gaining learner } \\
\text { attention; providing adequate guidance; } \\
\text { motivating; } \\
\text { - More exploratory rather than expository; }\end{array}$ \\
\hline Interaction Design & $\begin{array}{l}\text { Learner-Interface } \\
\text { interaction } \\
\text { Learner-Content } \\
\text { interaction }\end{array}$ & $\begin{array}{l}\text { - Appropriate use of hyperlinks for } \\
\text { simplicity, flexibility and user control } \\
\text { - Variety of frequent interactions - } \\
\text { activities/quizzes/ games } \\
\text { - User-friendly and motivating - } \\
\text { graphics/animations/audio/video } \\
\text { - Notice board, discussion forum, Wiki, } \\
\text { e-mail link }\end{array}$ \\
\hline
\end{tabular}




\begin{tabular}{|l|l|l|}
\hline Interface Design & Visual layout & $\begin{array}{l}\text { - Simple background with blending } \\
\text { colour scheme }\end{array}$ \\
& & $\begin{array}{l}\text { - Avoid over-crowding, consistency } \\
\text { - Readability, clarity, emphasis, motivating } \\
\text { - Appropriate integration of different } \\
\text { media elements }\end{array}$ \\
\hline
\end{tabular}

Table 2 Considerations for design features during Design and Development Phase

Since the concept of OER is still quite new for the targeted group, the importance of having an initial section on awareness-raising and basic guidance on OER use was highlighted. Furthermore, the need to provide selected OER based on the existing competency-based national school curriculum in a structured manner was stressed, in order to facilitate teachers to easily integrate with their day-to-day teaching. In addition, providing them the facility to search and identify additional resources as well as the ability to create and share their own resources was considered important.

The formative evaluations of the draft version of the prototype of OER $4 S c E d$ provided important feedback to revise and improve it in various aspects. Some important features identified as desirable are, structuring the content under the competencies stated in National School Curriculum of Science making it relevant and meaningful for the teachers, keeping the simplicity and consistency in design and navigation, structuring content in manageable amounts of information, provision of meaningful interactivity and making an appealing visual presentation to motivate users. Task focus was identified as a crucial design element, where challenging activities should be provided to encourage exploration, discovery, collaboration, reflection and self-regulated learning.

It was also identified that allowing and encouraging student teachers/teacher educators to work collaboratively with their instructors in this initiative as a team enable both parties to face challenges together, in this novel experience of designing an OLE on OER.

\section{Conclusion}

The initial stages in the process of analysis, design and development of $O E R 4 S c E d$ as a resource to enhance adopt, adapt and create OER by teachers is experienced as a challenging, yet a productive effort among a team of educators who are engaged in a series of cooperative and collaborative activities.

Structuring of information on OER related to teaching science while making it relevant and meaningful for teachers; use of exploratory instructional strategies enabling teachers to select OER; and use of different media elements to make the visual layout motivating, were identified as processes and structures that will best facilitate teachers to identify, adopt and adapt 
OER, while ensuring that the content is relevant and adaptable to user needs. Incorporating challenging online activities to facilitate frequent interactions among teachers encouraging them to adopt, adapt, create and share OER was identified as desirable to facilitate user engagement and collaboration in content creation.

Supporting the findings of previous studies, shared, collaborative and peer-based practices that replicate the characteristics of OER themselves, are playing a key role in the successful implementation of project activities (ISKME, 2008; TESSA, 2010). The critical and constructive self-reflections and peer reviews were very valuable in identifying and rectifying the shortcomings of $O E R 4 S c E d$. Especially, the participatory research approach with shared responsibilities among the project team consisting of instructors and student teachers/teacher educators of Faculty of Education proved to be extremely beneficial. It affirms the fact that creating and sharing OER is essentially about team work (Butcher, 2011), and that when adequately supported, students have great potential to support higher education providers in sourcing, adapting and producing OER in partnership with academic staff UNESCO (2011). The self-satisfaction gained through engaging in this novel experience is a motivation for educators in the team to move forward with the intention of completing this project successfully.

Shironica Karunanayaka (email: spkar@ou.ac.lk), Chandana Fernando (email: mnfer@ou.ac. lk) and Vajira de Silva (email: dvsil@ou.ac.lk) are with the Faculty of Education, The Open University of Sri Lanka.

\section{References}

Albright, P. (2005). UNESCO (iiep): Final forum report. Retrieved from http://learn. creativecommons.org/wp-content/uploads/2008/03/oerforumfinalreport.pdf on 23 October 2011.

Atkins, D. E., Brown, J. S., \& Hammond, A.L. (2007). A review of the open educational resources (OER) movement: Achievements, challenges, and new opportunities. Retrieved from http://www.hewlett.org/uploads/files/ReviewoftheOERMovement.pdf on 23 October 2011.

Butcher, N. (Author), Kanwar, A. (Ed.), \& Uvalic '-Trumbic ', S. (Ed.). (2011). A basic guide to open educational resources (OER). Vancouver: Commonwealth of Learning, and Paris, France: UNESCO. Retrieved from http://www.col.org/oerBasicGuide on 23 October 2011.

ISKME (2008) Creating, Doing and Sustaining OER: Lessons from six open educational resource projects. Retrieved from http://wiki.oercommons.org/mediawiki/upload/OER_ CASE_STUDY_WHITE_PAPER_pdf on 16 October 2011.

Hatakka, M. (2009). Build it and they will come? - Inhibiting factors for reuse of open content in developing countries. EJISDC 37(5), 1 -16. Retrieved from http://www.ejisdc. org/ojs2/index.php/ejisdc/article/view/545/279 on 23 October 2011. 
Joyce, A. (2007). OECD Study of OER: Forum Report, OECD 2007-09-01. Retrieved from http://www.unesco.org/iiep/virtualuniversity/forumsfiche.php?queryforumspages_id= 33 on 23 October 2011.

Kanjilal, U. (2007, May) Developing Digital Learning Repository: A case for eGyanKosh. Indian Journal of Open Learning, 16(2), 159-166.

Karunanayaka, S. \& Thanaraj, T. (2010, August). An indepth study on the design features adopted in the online courses developed in Moodle at the Faculty of Education. Paper presented at the International Research Conference at OUSL, Nawala, Sri Lanka.

Karunanayaka, S. (2005, December). Teachers as designers and developers of computer-assisted learning materials. Paper presented at the $61^{\text {st }}$ SLAAS Annual Sessions, OUSL, Nawala, Sri Lanka.

Karunanayaka, S. (2006, October/November) First Experiences in Collaborative Online Learning: A Case Study. Paper presented at The Fourth Pan-Commonwealth Forum on Open Learning (PCF4), Jamaica.

Karunanayaka, S. (2008a). Introducing an online learning course at the Open University of Sri Lanka. In K. Rama, A. Hope \& U. Coomaraswamy (Eds.) Quality Assurance Toolkit: Distance Higher Education Institutions \& Programmes. New Delhi: NAAC.

Karunanayaka, S. (2008b) Designing an online learning community among teacher educators. AAOU Journal, 3,(2), $71-82$.

Lane, A. Connolly, T., Ferreira, G. McAndrew, P. \& Wilson, T. (2010). Reusing, Reworking and Remixing Open Educational Resources. In Wanjira Kinuthia and Stewart Marshall (Eds), Cases ' $n$ ' Places: Global Cases in Educational and Performance Technology (pp 71 -84). NC: Information Age Publishing Inc.

Misra, P. K. (2011, September). OER: By the Teachers; For the Teachers, Of the Teachers. Paper presented at the AAOU Annual Conference, Penang, Malaysia.

MIT OCW (2007). MIT Open CourseWare-Our history. Retrieved from http://ocw.mit.edu/ OcwWeb/Web/about/history/index.htm on 23 October 2011.

Morimoto, Y. \& Yamada, T. (2011, September). OCW and OER Activities at the Open University of Japan. Paper presented at the AAOU Annual Conference, Penang, Malaysia.

OECD (2007). Giving knowledge for free. The emergence of open educational resources. Retrieved from http://213.253134.43/oecd/pdfs/browseit/9607041E.PDF on 23 October 2011. 
Singh, N. (2011, September). Training the elementary education professional for developing the Open Educational Resources. Paper presented at the AAOU Annual Conference, Penang, Malaysia.

Thomas, M.V., \& Kothari, R.G. (2011, September) An evaluation of Open Educational Resources with the Digital Repositories of the Indira Gandhi National Open University, India. Paper presented at the AAOU Annual Conference, Penang, Malaysia.

UNESCO (2002). Final Report. Forum on Impact of Open CourseWare for Higher Education in Developing countries. Retrieved from http://portal.unesco.org/ci/en/ev.phpURL_ID=5304\&URL_DO=DO_TOPIC\&URL_SECTION=201html on 23 October 2011.

UNESCO (2011). UNESCO-COL Guidelines for Open Educational Resources (OER) in Higher Education. Retrieved from http://unesdoc.unesco.org/images/0021/002136/213605e. pdf on 23 October 2011.

Wiley, D. (2006). The current state of open educational resources. Retrieved from http:// opencontent.org/blog/archives.247 on 23 October 2011.

Wolfenden, F., Buckler, H.A.S., \& Keraro, F. (2012). OER Adaptation and Reuse across cultural contexts in Sub Saharan Africa: Lessons from TESSA (Teacher Education in Sub Saharan Africa). Journal of Interactive Media Education. Retrieved from http://www-jime. open.ac.uk/jime/article/view/2012-03 on 1 August 2012. 